\title{
Erico Verissimo e a forma do playground iceberg, na leitura de C. Minchillo
}

Ieda Lebensztayn

Falta uma tristeza de menino bom caminhando entre adultos na esperança da justiça que tarda - como tarda! a clarear o mundo.

(Carlos Drummond de Andrade, "A falta de Erico Verissimo", Discurso de primavera e algumas sombras (1977))

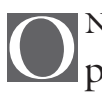

NDE CARROS são incapazes de atropelar, cobras não mordem, crianças anãs, sardentas, aprendem a conviver com as diferenças, todas carecas, um olho preto e o outro azul? Idealizado por Graciliano Ramos em 1937 ao sair da prisão, com o inferno nos olhos e a cabeça raspada, tal mundo foi o céu, mesmo efêmero, de Raimundo Pelado, que sofria caçoadas por ser diferente. $\mathrm{E}$ quem deu a público em livro $A$ Terra dos Meninos Pelados (Ramos, 1939), pela editora Globo, foi Erico Verissimo, que, além de romancista, atuou como editor, também tradutor, professor, palestrante e burocrata da diplomacia (diretor do Departamento Cultural da União Pan-Americana).

Tal fato - divulgar em livro um ideal humanista, carregado do respeito entre as pessoas e da consciência dos limites da realidade - é evocado aqui como síntese da trajetória de Erico Verissimo (19051975), cujos humanismo e angústias Carlos Minchillo acompanha, num estudo realizado com paixão e seriedade.

O título do livro, Erico Verissimo, escritor do mundo: circulação literária, cosmopolitismo e relações interamericanas, concentra os elementos da ambiguidade experienciada pelo romancista entre as faces ética e imperialista presentes no cosmopolitismo. E o crítico apreende momentos de inflexão em que tal ambiguidade se adensa em conflitos, apresentando-os aos leitores com precisão e clareza, ancoradas em seu vasto conhecimento da obra e do acervo do escritor, que consta do Instituto Moreira Salles (IMS) no Rio de Janeiro.

Veja-se que, em "escritor do mundo", o mundo é o objeto da escrita: observador, Erico buscou conhecê-lo, compreendê-lo e nele projetou seus anseios, dando forma a sua perspectiva ao criar seu mundo ficcional; ao mesmo tempo, o mundo é o lugar vasto, o plano para além do nacional, a que o artista se empenhou por pertencer. Aqui já se está na órbita do cosmopolitismo, e a própria palavra carrega duplicidade. Cosmopolita é etimologicamente o cidadão do mundo, aludindo, por um lado, a um teor de ética, de relações respeitosas em qualquer lugar; por outro, o cosmopolitismo pode significar a perda de uma identidade original, em nome de um artificialismo e de interesses consumistas de grandes centros, e daqui decorrem os sentidos negativos do imperialismo. 
Entender essas contradições do cosmopolitismo na trajetória de Erico Verissimo e a configuração delas em sua obra move a pesquisa e a reflexão exemplares de Minchillo.

Junto com o título do livro, a epígrafe escolhida dá a dimensão do humanismo que marca o cosmopolitismo de Verissimo, afinal o "escritor do mundo" se define como um contador de histórias, afeito a compreender figuras humanas, situadas num espaço e momento históri$\mathrm{co}$, marcadas por memórias, por inquietações do presente e por possibilidades de diálogo com o outro e de transformações: "Ninguém pode falar de ninguém sem contar uma história. Nenhuma figura humana pode ser estudada em termos literários num vácuo, pois ela pertence a um tempo e a um espaço, tem um passado, vive um presente. É também um contínuo devir, um processo transitivo e não um produto acabado". ${ }^{1}$

Contar histórias é a forma por meio da qual Erico Verissimo se lança a representar a realidade, expressando suas angústias ante os conflitos humanos e abrindo-se à comunicação com o outro. Essa formulação, que se pode projetar da epígrafe para o conjunto do estudo de Carlos Minchillo, tem como pressuposto crítico, aprendido de ensaios teóricos e analítico-interpretativos de Alfredo Bosi (1991, 2006, 2009), as quatro vertentes da obra de arte, cuja leitura, antidogmática, perfaz o círculo hermenêutico: a vertente de construção formal, a de representação histórico-social, a de expressão subjetiva e a da recepção crítica, de transitividade com o leitor.

A originalidade da abordagem de Carlos Minchillo advém de centrar-se em obras cujos enredos se situam para além das fronteiras do Brasil: Saga (1940), O senhor embaixador (1965) e O prisioneiro (1967). Compostas num intervalo de 27 anos, acompanham continuidades e mudanças do olhar e dos sentimentos de Erico Verissimo em relação aos contextos históricos e espaciais representados, suas esperanças e decepções. Nesse sentido, cumpre assinalar que, resultado do talento e empenho de Minchillo como pesquisador de arquivos e intérprete de textos literários e de seus contextos históricos, quer de sociabilidade intelectual, quer de conflitos políticos nacionais e internacionais, o livro Erico Verissimo, escritor do mundo combina organicamente vários aspectos analíticos, voltados para o eixo cosmopolitismo/humanismo, que decerto atrairão o interesse do público: uma depurada leitura dos romances mencionados de Verissimo, com incursões também por anteriores, como Clarissa (1933), Caminhos cruzados (1935), Música ao longe (1936) e Um lugar ao sol (1936), e pelas obras México (1957), relato de viagem, e Brazilian Literature: an Outline (1945), compêndio de literatura; uma pesquisa atenta de sua correspondência ativa e passiva, presente no acervo do IMS; o evocar de passagens dos volumes de memórias Solo de clarineta $(1973,1976)$ e da biografia Um certo Henrique Bertaso (1972); uma comparação entre os dois livros de viagem aos Estados Unidos, Gato preto em campo de neve (1941) e $A$ volta do gato preto (1943); diálogos com a fortuna crítica do escritor; reflexões, com embasamento nos romances e em estudos historiográficos, sobre os anos da Guerra Civil Espanhola, da Segunda Guerra Mundial, da guerra fria, as tensões sociais e políticas dos países latino-americanos, a questão racial dos negros norte-americanos; uma discussão a res- 
peito do mercado editorial e da recepção crítica da literatura brasileira.

Em especial, o movimento comparativo entre os dois livros de viagem aos Estados Unidos dá a medida das referidas mudanças de matizes pelas quais passou Erico Verissimo. É perspicaz o título da seção referente a esse cotejo: "De volta à América ou impressões de um gato escaldado". Minchillo detecta, entre Gato preto em campo de neve (1941) e $A$ volta do gato preto (1943), o tom menos deslumbrado do escritor, e faz conjecturas quanto às motivações que o tornaram gato escaldado: sugere desgostos de Verissimo com a situação política e intelectual brasileira durante o Estado Novo, sua percepção de aspectos problemáticos dos Estados Unidos, o envolvimento emocional com a brutalidade da guerra, a decepção com as promessas da política de boa vizinhança.

Esse ponto de inflexão a partir dos dois relatos de viagens aos Estados Unidos define o terceiro capítulo do livro de Minchillo, "Um camelô do pan-americanismo": depreendendo as hesitações de Verissimo quanto a tal função de camelô, de promotor da boa vizinhança, o crítico observa que o senso de esperança, marca do escritor, passava a ser ambíguo. Retomar aqui esse ponto de inflexão possibilita lançar luz ao todo do livro. Ele se organiza em quatro capítulos, que justamente apresentam e adensam faces dessa ambiguidade de Erico Verissimo entre adesão e distanciamento em sua experiência fora do Brasil.

Significativamente intitulado "O escritor com um pé lá fora", o primeiro capítulo, situando a posição excêntrica de Erico nas letras brasileiras dos anos 1930 e 1940, nem modernista nem regionalista, sublinha a sua sensibilidade cosmo- polita: como escritor, tradutor, editor e intelectual itinerante, atuou na interface do local e do internacional. Tanto em seus textos como em suas atividades no exterior, contribuiu para a abertura do romance brasileiro ao cenário mundial. Minchillo nos informa que, dos seis romances brasileiros traduzidos e publicados nos Estados Unidos durante a década de 1940, três eram de Verissimo: Caminhos cruzados, $O$ resto é silêncio e Olhai os lírios do campo. E sugere um paralelo, depois retomado, com Monteiro Lobato, que merece destaque: ambos os escritores foram best-sellers, dedicaram-se ao trabalho de editores, conscientes do valor mercadológico dos livros e de seu valor artístico, necessários para a formação cultural brasileira, e voltaram o olhar para a importância dos Estados Unidos no cenário mundial.

Retomando aqui o pressuposto hermenêutico das quatro dimensões da arte, é preciso salientar algumas imagens analisadas por Minchillo, que incitam a buscar os livros de Verissimo: os círculos de giz, o iceberg, o playground, o prédio-fóssil. Elas constituem eixos de construção formal dos romances, em que se amalgamam a expressão de conflitos subjetivos e a representação de relações sócio-históricas.

No segundo capítulo, "A modernidade sitiada: trajetórias e deambulações nos primeiros romances de Erico Verissimo", Minchillo se detém em Clarissa, Um lugar ao sol e Saga, acompanhando, especialmente a partir das imagens do aquário, do círculo de giz e da engrenagem capitalista, as oscilações das personagens entre imobilismo e abertura para o outro, para os homens em guerra. A leitura dessas obras, que constituem um "romance-rio", lhe permite identificar como o es- 
critor caminhava para uma "percepção mais complexa dos liames sociais e históricos em jogo nas atitudes humanas".

$\mathrm{E}$, depois da referida análise das mudanças de Erico ao longo dos dois relatos de viagem aos Estados Unidos, o quarto capítulo, "O império, a guerrilha e o humanismo destroçado", desvela a intensificação de seu viés crítico contra o imperialismo e o neocolonialismo. Forte, a expressão "humanismo destroçado" traduz a descrença que Minchillo reconhece no escritor depois da terceira estada em solo norte-americano, entre 1953 e 1956, como diretor do Departamento Cultural da União Pan-Americana. Tem então lugar o estudo de México, $O$ Senhor Embaixador e $O$ prisioneiro, em que se destacam vários momentos analítico-interpretativos.

Do segundo desses livros sobressai a imagem do iceberg, que garante a Minchillo observar como se afinou a percepção da realidade de Erico, de idealista a desconfiada. Imagem "poderosa", o iceberg é uma forma que representa sua consciência de existirem, sob os fatos visíveis, motivações sociais e subjetivas submersas, um "torvo oceano de interesses políticos e econômicos, egoísmos e apetites nacionais e individuais", nas palavras do personagem William B. Godkin, jornalista especializado em assuntos latino-americanos. Também a imagem do subsolo do playground indica que o jardim ocidental é ilusório, fermenta cemitérios. Em O Senhor Embaixador, a comunhão diplomática não passa de superficialidade, ponta de um iceberg a sinalizar a consciência trágica de que a política de boa vizinhança e o colorido cosmopolita escondem interesses financeiros, tensão racial, violência, barbárie.
Igualmente a análise de imagens e figuras de $O$ prisioneiro prende a atenção do leitor: Minchillo surpreende, na descrição de um prédio cor de osso onde ficavam oficiais do exército norte-americano solteiros, a figuração de um fóssil de silenciada hecatombe - representação crítica e expressão angustiosa da guerra do Vietnã. O crítico salienta ser a doença a marca das personagens desse romance (a professora francesa, a prostituta $\mathrm{K}$, $\mathrm{O}$ tenente), forma a conjugar a esfera privada e a situação (neo)colonial: os dramas psicológicos estão entrelaçados à questão política, bélica. Com atualidade assustadora, as questões de terrorismo, intolerância, preconceito racial e violência culminam numa imagem do sem saída: o que parecia um livro era na verdade combustível de um suicida.

Nas "Considerações finais", Minchillo retoma a reflexão quanto à quarta vertente das obras de arte, da transitividade com o leitor. Se as três vertentes hermenêuticas foram apreendidas de maneira fecunda por Alfredo Bosi a partir da fortuna crítica machadiana, também seu olhar para a quarta vertente encontra inspiração em estudo sobre Machado de Assis: Os leitores de Machado de Assis: o romance machadiano e o público de literatura no século 19, de Hélio de Seixas Guimarães (2012), o orientador da tese de doutorado que originou o livro de Minchillo. Enriquecido agora da pesquisa e das análises a respeito da trajetória de Erico Verissimo, repõe-se o problema crítico de compreender os fatores das oscilações da recepção da literatura do romancista entre momentos de grande alcance nacional e internacional e outros de esquecimento; além dos critérios relativos à forma literária, tanto o vínculo com os Estados Unidos como 
o socialismo apartidário podem ter despertado resistência ou atração. Minchillo partilha com o leitor incertezas e caminhos para pensar sobre as motivações que interferem na comunicação da arte com o público - as questões de gosto, a construção da universalidade, o valor literário, condições históricas, linguísticas, culturais, posições ideológicas, interesses editoriais, relações de sociabilidade, a atuação do escritor, da crítica e da imprensa.

Conforme Kátia Gerab Baggio observa no esclarecedor prefácio do livro, Carlos Minchillo fez uma aposta arriscada, porém exitosa, ao deixar de lado a trilogia $O$ tempo e o vento e se debruçar sobre a experiência cosmopolita do escritor. Essa aposta num viés original resultou num estudo consistente e com força de atualidade, voz contra as violências do mundo. Isso porque pautado pela tradição crítica, pela própria obra de Verissimo e pelo seu desejo de internacionalização da literatura brasileira - conjunto de fatores que, numa síntese significativa, permitem a Minchillo justificar a assinatura sem acentos do nome do escritor.

Assim, além de contribuir para a fortuna de Erico Verissimo e para os estudos das relações interamericanas sobretudo a partir dos anos 1940, o livro de Carlos Minchillo, ao tomar como problema os impasses vividos e configurados em arte por um escritor brasileiro no exterior, entre o ímpeto cosmopolita e a consciência anti-imperialista, indaga eticamente pelo papel da literatura em meio aos interesses econômicos dos homens e aos conflitos políticos das nações. Instiga a tarefa hermenêutica: a conhecer e compreender melhor as criações de um escritor, a (re)ver a história, a encontrar imagens que falem contra os preconceitos e a barbárie. Instiga a desentranhar, de uma imagem, de uma palavra, de um escritor aparentemente gastos, significados renovados (Silva, 1996, p.53-66), mesmo que devido à repetição trágica da história. Como a lâmpada acesa por Erico Verissimo (2005, p.65): “Desde que, adulto, comecei a escrever romances, tem-me animado até hoje a ideia de que o menos que um escritor pode fazer, numa época de atrocidades e injustiças como a nossa, é acender a sua lâmpada, fazer luz sobre a realidade de seu mundo, evitando que sobre ele caia a escuridão, propícia aos ladrões, aos assassinos e aos tiranos. Sim, segurar a lâmpada, a despeito da náusea e do horror" (apud p.247).

Nota

1 Erico Verissimo em entrevista a João Alves das Neves, "Erico Verissimo, o Solo da Liberdade", Banas, São Paulo, n.1069, p.41-7, 7 out. 1974, apud Minchillo (2015, p.19).

\section{Referências}

BOSI, A. Reflexões sobre a arte. 4.ed. São Paulo: Ática, 1991

Brás Cubas em três versões. São Paulo: Cia. das Letras, 2006.

Machado de Assis na encruzilhada dos caminhos da crítica. Machado de Assis em Linha, ano 2, n.4, dez. 2009. Disponível em: <http://machadodeassis. fflch.usp.br/node/12>. Acesso em: 22 nov. 2015.

GUIMARÃES, H. de S. Os leitores de Machado de Assis: o romance machadiano e o público de literatura no século 19. 2.ed. São Paulo: Nankin; Edusp, 2012.

MINCHILLO, C. C. Erico Verissimo, es- 
critor do mundo: circulação literária, cosmopolitismo e relações interamericanas. São Paulo: Edusp, 2015.

RAMOS, G. A Terra dos Meninos Pelados. Ilustrações de Nelson Boeira Faedrich. Porto Alegre: Globo, 1939.

SILVA, F. L. e. A dimensão ética da palavra. Tempo Social: Revista de Sociologia da USP, São Paulo, v.8, p.53-66, 1996.

VERISSIMO, E. Solo de clarineta. São Paulo: Cia. das Letras, 2005. v.1, p. 65.

Ieda Lebensztayn é pesquisadora de pósdoutorado na Biblioteca Brasiliana Mindlin (BBM-USP), Faculdade de Filosofia, Letras e Ciências Humanas da USP (Processo CNPq 166032/2015-8).

@ - biolito@gmail.com

Recebido em 9.8.2016 e aceito em 18.9.2016.

I Faculdade de Filosofia, Letras e Ciências Humanas, Universidade de São Paulo, São Paulo / São Paulo, Brasil. 